\title{
Effect of $\mathrm{Mg}_{17} \mathrm{Al}_{12}$ Fraction on Mechanical Properties of Mg-9\%Al-1\%Zn Cast Alloy
}

\author{
Hoda Dini *, Nils-Eric Andersson and Anders E.W. Jarfors \\ Department of Materials and Manufacturing, School of Engineering, Jönköping University, Casting, \\ P.O. Box 1026, Jönköping SE-551 11, Sweden; Nils-Eric.Andersson@ju.se (N.-E.A.); \\ Anders.Jarfors@ju.se (A.E.W.J.) \\ * Correspondence: hoda.dini@ju.se; Tel.: +46-36101927
}

Academic Editor: Hugo F. Lopez

Received: 4 September 2016; Accepted: 18 October 2016; Published: 24 October 2016

\begin{abstract}
In the current study it was observed that the offset yield point of $\mathrm{Mg}-9 \% \mathrm{Al}-1 \% \mathrm{Zn}$ alloy was strongly influenced by the connectivity of $\mathrm{Mg}_{17} \mathrm{Al}_{12}$. It was suggested that an increase in the fraction of $\mathrm{Mg}_{17} \mathrm{Al}_{12}$ from $8 \%$ to $11 \%$ could lead to the formation of a $\mathrm{Mg}_{17} \mathrm{Al}_{12}$ network which resulted in a higher offset yield point. In addition, it was observed that elongation to failure of the $\mathrm{Mg}-9 \% \mathrm{Al}-1 \% \mathrm{Zn}$ alloy strongly depended on the fraction of $\mathrm{Mg}_{17} \mathrm{Al}_{12}$. Moreover, the apparent toughness showed a strong inverse relation to the secondary dendrite arm spacing. This approach might be extended to forecast the behavior in other magnesium alloys forming a network of the Mg-Al phase.
\end{abstract}

Keywords: casting; microstructure; tension test; magnesium alloys; mechanical properties

\section{Introduction}

Cast Mg-9\%Al-1\%Zn (AZ91D) has a good combination of castability and mechanical strength with a fair corrosion resistance, which makes it attractive for use in automotive components [1]. Significant progress has been seen in casting capability and understanding of the relation between the microstructure and mechanical properties of AZ91. These relations were established experimentally [2-4] and modeled for quantitative prediction [5-7]. The microstructure of AZ91D consists of the primary $\alpha-\mathrm{Mg}$ and a highly divorced eutectic consisting of $\alpha-\mathrm{Mg}$ and $\mathrm{Mg}_{17} \mathrm{Al}_{12}$. The fraction and morphology of the intermetallic phase, $\mathrm{Mg}_{17} \mathrm{Al}_{12}$, is heavily influenced by the non-equilibrium nature of the solidification and thus also by the choice of casting method and its associated process conditions [8]. It has been demonstrated that the morphology, distribution and volume fraction of $\mathrm{Mg}_{17} \mathrm{Al}_{12}$ affect the mechanical strength of AZ91D [9]. Moreover, it was suggested that a highly interconnected network of $\mathrm{Mg}_{17} \mathrm{Al}_{12}$ may account for the increased creep strength of other $\mathrm{Mg}$ alloys [10]. Nagasekhar et al. [11] studied the three-dimensional characteristics of $\mathrm{Mg}_{17} \mathrm{Al}_{12}$ in High Pressure Die Cast (HPDC) AZ91 and showed that the connectivity of $\mathrm{Mg}_{17} \mathrm{Al}_{12}$ intermetallic could be seen in the as-cast material.

It has also been implied that increasing the area fraction of $\mathrm{Mg}_{17} \mathrm{Al}_{12}$ may lead to an increased microhardness and macrohardness of HPDC AZ91D alloy [3,12]. Cao et al. [13], on the other hand, reported that there is no evidence that $\mathrm{Mg}_{17} \mathrm{Al}_{12}$ affects the hardness of $\mathrm{AZ91}$. In addition, there is no clear influence of $\mathrm{Mg}_{17} \mathrm{Al}_{12}$ content on the yield point of AZ91D alloy. Cáceres et al. [3] implied that there is no meaningful Hall-Petch grain size effect on the yield stress of HPDC AZ91. Dini et al. found that the yield point displayed a strain rate dependence but this depended on the fraction of $\mathrm{Mg}_{17} \mathrm{Al}_{12}$ [14].

The current knowledge of the mechanical behavior of AZ91D clearly indicates a gap in our understanding of (i) the effect of $\mathrm{Mg}_{17} \mathrm{Al}_{12}$ connectivity and (ii) the effect of grain size as well as (iii) secondary dendrite arm spacing (SDAS) on mechanical properties. Hence, the main objective of 
the current study is to improve our understanding of the effect of the microstructure on the tensile behavior of AZ91D by casting a range of microstructures corresponding to the coarse microstructure found in slowly cooled, sand-cast components to the fine microstructures typical of the higher cooling rates found in HPDC-processed AZ91D. The focus of this study is to understand the relationship between, in particular, SDAS, grain size, $\mathrm{Mg}_{17} \mathrm{Al}_{12}$ and yield stress. In addition, the relation of the elongation to fracture and the fraction of $\mathrm{Mg}_{17} \mathrm{Al}_{12}$ was determined for the temperature range of $25^{\circ} \mathrm{C}$ up to $190{ }^{\circ} \mathrm{C}$.

\section{Material and Methods}

In this study, the design of experiments (DOE) and D-optimal method was used as a scientific approach for exploring the effect of variables. The DOE approach allows the study of the influence of individual factors and the mutual interactions between factors on desired properties within the chosen concentration working range. DOE provides a route to obtain the optimal formulations, and to get the needed information with the minimum number of experiments. The DesignExpert ${ }^{\mathrm{TM}}$ software (Stat-Ease, Minneapolis, MN, USA) was used to assist in the DOE and the statistical evaluation of collected data. The variable factors were Bridgeman furnace pull rate ranging from $0.3 \mathrm{~mm} / \mathrm{s}$ to $6 \mathrm{~mm} / \mathrm{s}$ (identical to the solidification speed), tensile properties from room temperature (RT) up to $190^{\circ} \mathrm{C}$ and strain rates form $10^{-4}$ to $10^{-1} 1 / \mathrm{s}$. The established experimental plan obtained by DOE is shown in Table 1. Each particular test condition is identified by a run number ( $R$ (run number)) and the number of replicates is shown in brackets. For example, R1:(4) is identified as the run 1 and the replications of this run is 4 times.

Commercial grade AZ91D ingots were melted in a mild steel crucible, under dry air atmosphere with $0.5 \% \mathrm{SF}_{6}$ gas. Rods for remelting in a Bridgeman furnace, were fabricated by sucking the melt into $1000 \mathrm{~mm}$ long, $10 \mathrm{~mm}$ diameter mild steel tube, preheated to $250^{\circ} \mathrm{C}$. This method, ensured the fabrication of clean AZ91D rods for further processing. The fabricated rods were cut into lengths of $170 \mathrm{~mm}$ and re-melted in a Bridgman furnace under the protective atmosphere $\left(0.5 \% \mathrm{SF}_{6}\right.$ in dry air). These rods were held at $650{ }^{\circ} \mathrm{C}$ sufficiently long to ensure complete melting and subsequently resolidified unidirectionally in the Bridgmen furnace under constant solidification speed. In this study, the solidification rate was controlled by adjusting the pull rate of the furnace from $0.3 \mathrm{~mm} / \mathrm{s}$ to $6 \mathrm{~mm} / \mathrm{s}$.

The tensile properties were measured according to ASTM B557 [15] on cylindrical sub-sized tensile bar with a reduced section of $6 \mathrm{~mm}$ and a gauge length of $36 \mathrm{~mm}$ using a ZWICK-ROLL ${ }^{\text {TM }}$ Z100 tensile testing machine (ZwickGmbH \& Co. KG, Ulm, Germany) equipped with a Laser extensometer. Tensile tests were performed at room temperature (RT) up to $190{ }^{\circ} \mathrm{C}$ and at strain rates ranging from $10^{-4}$ up to $10^{-1} 1 / \mathrm{s}$.

Samples for microstructural characterization were prepared following standard procedures [16]. Specimen cross-sections were etched at room temperature using $10 \mathrm{~mL} \mathrm{HF} \mathrm{(48 \% )} \mathrm{for} \mathrm{1-2} \mathrm{s} \mathrm{to} \mathrm{etch}$ and color the $\mathrm{Mg}_{17} \mathrm{Al}_{12}$ dark [17]. According to ASTM E112 [18] when determining the particle size (diameter), two transversal lengths having perpendicular directions to each other were drawn on each particle in the micrograph, and the average of at least six lengths was reported as the diameter of the particle $[19,20]$. Normally, at least 100 diameter measurements were made in each sample. The area fraction of phases was measured by using an Olympus Stream ${ }^{\mathrm{TM}}$ motion 1.8 image analysis system (Olympus, Tokyo, Japan), based on image contrast in five images per sample. The shape factor of particles was obtained from the $4 \pi A / p^{2}$ relation where $A$ and $p$ are the area and perimeter of particles respectively following ISO, 9276-6: 2008 (E) [21]. The SDAS was determined using light-optical microscope (Olympus, Tokyo, Japan) by measuring more than 50 dendrite arms for each specimen (for sufficient accuracy).

To measure the actual grain size electron back scatter diffraction (EBSD) was employed by using the JEOL JSM-7001F field emission scanning electron microscope (JEOL, Tokyo, Japan). The scanning step size of $0.8 \mu \mathrm{m}$ was employed to distinguish between secondary arms and primary grains. 
Table 1. Experimental conditions, microstructural feature size and mechanical properties obtained from a variety of pulling rates between $0.3 \mathrm{~mm} / \mathrm{s}$ and $6 \mathrm{~mm} / \mathrm{s}$. Each particular test condition is identified by a run number ( $R$ (run number)) and the number of replicates is shown in brackets. For example, R1:(4) is identified as run 1 and the replications of this run is four.

\begin{tabular}{|c|c|c|c|c|c|c|c|c|c|}
\hline \multirow{2}{*}{ Sample No. } & Solidification Rate & Test Temperature & Strain Rate & Grain Size & SDAS & $\mathrm{Mg}_{17} \mathrm{Al}_{12}$ Fraction & $R_{p 0.2}$ & $\boldsymbol{R}_{m}$ & $\varepsilon_{f}$ \\
\hline & $(\mathrm{mm} / \mathrm{s})$ & $\left({ }^{\circ} \mathrm{C}\right)$ & $(1 / \mathrm{s})$ & $(\mu \mathrm{m})$ & $(\mu \mathrm{m})$ & $(\%)$ & (MPa) & (MPa) & $(\%)$ \\
\hline R16:(8) & 6 & RT & 0.0001 & $100.5 \pm 0.3$ & $4.2 \pm 0.2$ & $8.5 \pm 0.4$ & $103.2 \pm 4.2$ & $230 \pm 6$ & $12 \pm 0.2$ \\
\hline R8:(8) & 6 & RT & 0.0001 & $102.4 \pm 0.4$ & $5.4 \pm 0.3$ & $7.1 \pm 0.2$ & $100.2 \pm 3.6$ & $223 \pm 10$ & $10 \pm 1.6$ \\
\hline R20:(4) & 0.3 & RT & 0.0001 & $295.4 \pm 0.6$ & $25.0 \pm 0.6$ & $11.0 \pm 0.9$ & $144 \pm 2.7$ & $250 \pm 9$ & $2 \pm 1.1$ \\
\hline $\mathrm{R} 2:(4)$ & 0.3 & RT & 0.03 & $303.2 \pm 0.5$ & $25.3 \pm 0.4$ & $11.3 \pm 0.3$ & $146.8 \pm 3.5$ & $209 \pm 4$ & $2 \pm 1.5$ \\
\hline R13:(4) & 0.3 & RT & 0.03 & $307.8 \pm 0.6$ & $23.7 \pm 0.5$ & $8.9 \pm 0.3$ & $107.7 \pm 1.8$ & $207 \pm 10$ & $4 \pm 0.8$ \\
\hline R18:(5) & 0.3 & RT & 0.03 & $287.6 \pm 0.5$ & $15.7 \pm 0.2$ & $10.6 \pm 0.2$ & $143.1 \pm 2.5$ & $224 \pm 12$ & $6 \pm 0.9$ \\
\hline R14:(8) & 6 & 89 & 0.06 & $103.4 \pm 0.2$ & $4.2 \pm 1.2$ & $7.1 \pm 0.4$ & 88.1 & 229 & $4.3 \pm 0.5$ \\
\hline R3:(8) & 6 & 89 & 0.06 & $95.1 \pm 0.5$ & $4.7 \pm 0.5$ & $7.8 \pm 0.7$ & $90.4 \pm 3.5$ & $258 \pm 4.5$ & $3.5 \pm 0.4$ \\
\hline R15:(8) & 6 & 89 & 0.1 & $98.4 \pm 0.2$ & $4.3 \pm 0.2$ & $6.8 \pm 0.5$ & 100.3 & 253 & 2.6 \\
\hline R4:(4) & 6 & 89 & 0.02 & $103.0 \pm 0.2$ & $4.5 \pm 0.2$ & $6.7 \pm 0.5$ & 94.2 & 245 & 2.3 \\
\hline R10:(4) & 6 & 89 & 0.0001 & $100.3 \pm 0.5$ & $4.2 \pm 0.3$ & $7.1 \pm 0.6$ & 104.9 & 257 & 4.3 \\
\hline R17:(6) & 0.3 & 120 & 0.04 & $304.5 \pm 1.2$ & $24.0 \pm 1.2$ & $11.5 \pm 0.6$ & 140.8 & 191 & 3.8 \\
\hline R14:(5) & 0.3 & 131 & 0.1 & $295.1 \pm 0.4$ & $23.0 \pm 0.4$ & $11.4 \pm 0.2$ & 139.8 & 211 & $2.6 \pm 0.6$ \\
\hline R9:(6) & 4 & 133 & 0.03 & $142.3 \pm 0.3$ & $6.7 \pm 1$ & $9.3 \pm 0.6$ & 102.8 & 241 & $3.4 \pm 0.2$ \\
\hline R21:(5) & 4 & 133 & 0.03 & $138.6 \pm 0.7$ & $6.4 \pm 1$ & $8.4 \pm 0.6$ & $92.9 \pm 3.5$ & $261 \pm 1.3$ & 3.1 \\
\hline R19:(5) & 6 & 190 & 0.0001 & $109.2 \pm 0.3$ & $6.3 \pm 0.4$ & $7.1 \pm 0.6$ & $70.7 \pm 5.3$ & $144 \pm 9.7$ & $12 \pm 1.3$ \\
\hline R22:1(6) & 6 & 190 & 0.0001 & $112.4 \pm 0.9$ & $7.4 \pm 0.6$ & $7.8 \pm 0.4$ & $75.6 \pm 4.5$ & $133 \pm 6$ & $10 \pm 0.6$ \\
\hline R6:(9) & 6 & 190 & 0.0001 & $146 \pm 0.9$ & $5.2 \pm 0.4$ & 8.3 & $77.2 \pm 2.8$ & $205 \pm 11$ & $16 \pm 1.3$ \\
\hline R23:(9) & 0.3 & 190 & 0.0001 & 331.3 & 22.5 & 12.3 & $108.9 \pm 3.5$ & $133 \pm 3$ & $6.1 \pm 1.1$ \\
\hline R1:(8) & 0.3 & 190 & 0.0001 & $321.6 \pm 0.6$ & $25.2 \pm 1.6$ & $11.9 \pm 0.9$ & $105.3 \pm 4.3$ & $139 \pm 6$ & $3.6 \pm 1.4$ \\
\hline R24:(8) & 0.3 & 190 & 0.0001 & $307.2 \pm 0.2$ & $23.4 \pm 1.6$ & $11.3 \pm 0.2$ & $101.9 \pm 3.4$ & $157 \pm 7$ & $5.4 \pm 1.3$ \\
\hline R7:(5) & 3 & 190 & 0.0001 & $214.6 \pm 0.3$ & $12.5 \pm 1.1$ & $8.8 \pm 0.9$ & $75.4 \pm 4.3$ & $130 \pm 5$ & $8.3 \pm 1.6$ \\
\hline
\end{tabular}




\section{Results and Discussion}

All quantitative data are collated in Table 1, together with the experimental conditions. Figure 1a,b shows typical microstructures obtained for the solidification rate of $6 \mathrm{~mm} / \mathrm{s}$ and $0.3 \mathrm{~mm} / \mathrm{s}$, respectively. The observed equiaxed microstructures contained $\alpha-\mathrm{Mg}$ (white phase) surrounded by $\mathrm{Mg}_{17} \mathrm{Al}_{12}$ (dark gray phase). Depending on the subsequent cooling rate, the amount of back diffusion in the solid phase may vary, giving rise to different amounts of remaining liquid for the eutectic reaction. The expected outcome is that a low solidification rate gives a result closer to equilibrium. The cooling rate has an effect on the secondary dendrite arm spacing (SDAS), the grain size, and the fraction of $\mathrm{Mg}_{17} \mathrm{Al}_{12}$ [22]. The morphology of the divorced eutectic structure is dependent on the cooling conditions. It has been reported that an increased drawing rate in $\mathrm{Mg}-\mathrm{Al}$ alloys promotes the formation of a more divorced eutectic $[13,23,24]$. It was observed that increasing the solidification rate led to a reduction in SDAS (see Table 1).
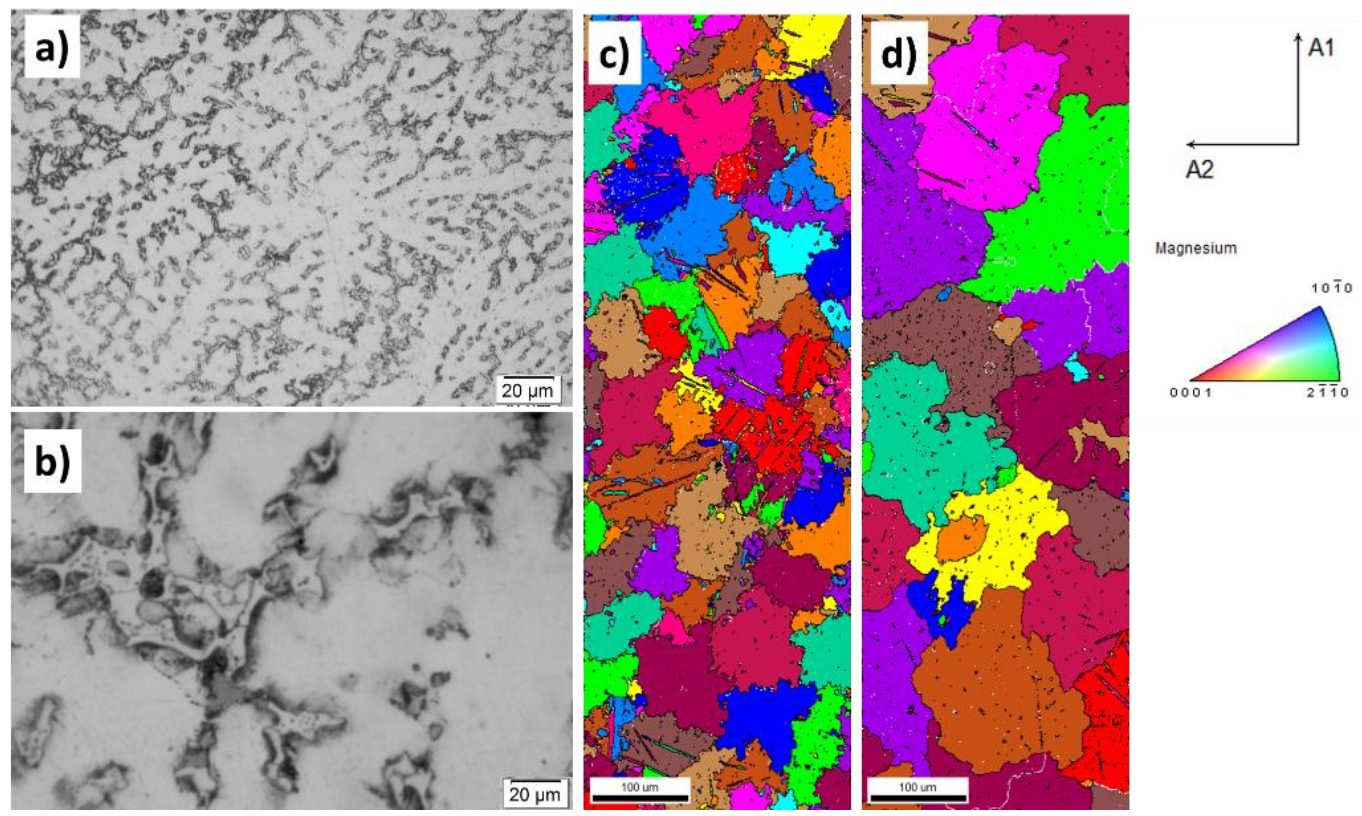

Figure 1. (a) Optical micrograph of samples drawn at $6 \mathrm{~mm} / \mathrm{s}$ (SDAS of $4.2 \pm 1.2 \mu \mathrm{m}$ ) and (b) samples drawn at $0.3 \mathrm{~mm} / \mathrm{s}$ (SDAS of $23.9 \pm 4.4 \mu \mathrm{m}$ ); (c) Illustration of IPF maps for samples drawn at $6 \mathrm{~mm} / \mathrm{s}$ (grain size of $93 \mu \mathrm{m} \pm 4.4 \mu \mathrm{m}$ ) and (d) sample drawn at $0.3 \mathrm{~mm} / \mathrm{s}$ (grain size of $254 \mu \mathrm{m} \pm 3.7 \mu \mathrm{m}$ ). Non-indexed regions (white regions) around the grain boundaries represent the $\mathrm{Mg}_{17} \mathrm{Al}_{12}$ phases. Non-indexed reigns inside the grains indicate defects and/or deformed area.

Inverse Pole Figure (IPF) maps of the samples are shown in Figure 1c,d. The maps illustrate a lack of texture, and the assumption of isotropic behavior in tensile testing could thus be made. Similar to SDAS, the higher solidification rate leads to finer grain sizes (see Table 1).

$\mathrm{Mg}_{17} \mathrm{Al}_{12}$ precipitated in a different morphology in the inter-dendritic regions. The size of the $\mathrm{Mg}_{17} \mathrm{Al}_{12}$ particles was measured. For the high solidification rate $(6 \mathrm{~mm} / \mathrm{s})$, the microstructural scale for $\mathrm{Mg}_{17} \mathrm{Al}_{12}$ ranged from $0.8 \mu \mathrm{m}$ to $16.5 \mu \mathrm{m}$. For the low solidification rate $(0.3 \mathrm{~mm} / \mathrm{s})$, this range was from $1.3 \mu \mathrm{m}$ to $24.2 \mu \mathrm{m}$. The shape factor (a value of one corresponds to a perfect sphere) of $\mathrm{Mg}_{17} \mathrm{Al}_{12}$ for different solidification speeds appeared to be independent of the solidification rate $(0.60 \pm 0.2)$, but the area fraction showed a significant variation. The wide range of the shape factor suggests that $\mathrm{Mg}_{17} \mathrm{Al}_{12}$ has a strongly elongated shape and is present at the intergranular regions. It was interesting to note that an increased solidification rate resulted in a decreased fraction of $\mathrm{Mg}_{17} \mathrm{Al}_{12}$ (see Table 1).

Figure $2 \mathrm{a}, \mathrm{b}$ shows typical true stress-strain curves for different SDASs and fractions of $\mathrm{Mg}_{17} \mathrm{Al}_{12}$ at room temperature and $190^{\circ} \mathrm{C}$, respectively. The chosen curves illustrate the most critical phenomena 
observed. The offset yield strength $\left(R_{p 0.2}\right)$ appeared to increase with the increased fraction of $\mathrm{Mg}_{17} \mathrm{Al}_{12}$. At a same strain rate, the sample with a high offset yield point is the one with a high amount of intermetallic (Figure 2a,b). It is worth mentioning that the influence of the strain rate on tensile properties was already studied and the results suggested that there is an interaction between the fraction of $\mathrm{Mg}_{17} \mathrm{Al}_{12}$ and the strain rate [14]. At a high strain rate, the effect of the $\mathrm{Mg}_{17} \mathrm{Al}_{12}$ fraction on yield strength is dominant, while no significant effect was observed at a lower fraction of $\mathrm{Mg}_{17} \mathrm{Al}_{12}$.
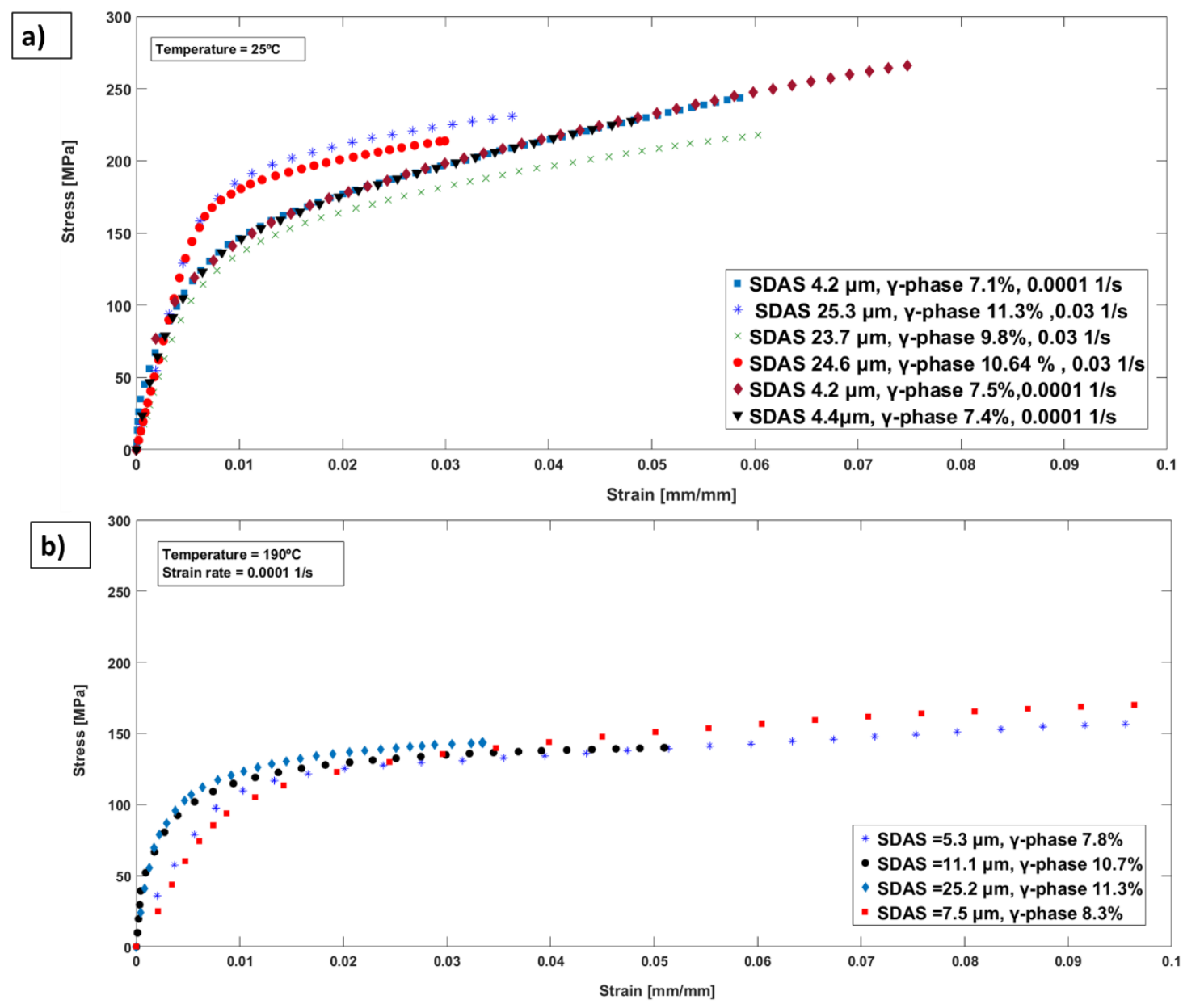

Figure 2. Stress-strain curves for specimens deformed at (a) room temperature, and (b) $190{ }^{\circ} \mathrm{C}$, and a strain rate of $0.00011 / \mathrm{s}$.

It is important to note that hardening appears higher for a lower fraction of $\mathrm{Mg}_{17} \mathrm{Al}_{12}$ and a smaller SDAS. This is in agreement with the findings of Cáceres et al. [12]. Furthermore, a higher fraction of $\mathrm{Mg}_{17} \mathrm{Al}_{12}$ appears to reduce the elongation to failure which also was found by Zhang et al. [25]. The ultimate tensile strength was mainly determined by temperature.

The average value of $R_{p 0.2}$ obtained for tensile tests at room temperature and $190{ }^{\circ} \mathrm{C}$ is plotted against the area fraction of $\mathrm{Mg}_{17} \mathrm{Al}_{12}$ in Figure 3a. It is seen that an increased fraction of $\mathrm{Mg}_{17} \mathrm{Al}_{12}$ caused an increase of the offset yield strength. Furthermore, Figure 3a shows that two different groups of behavior could be observed both at room temperature and at $190{ }^{\circ} \mathrm{C}$. It appears as both a change in slope and as a jump in the actual level of the dependence of $R_{p 0.2}$ with the fraction of $\mathrm{Mg}_{17} \mathrm{Al}_{12}$. This change of behavior appears as the fraction changes from approximately $9 \%$ up to $11 \%$. The possibility of having a network of $\mathrm{Mg}_{17} \mathrm{Al}_{12}$ was analyzed earlier through the thermal expansion of AZ91D [26]. Also, Nagasekhar et al. $[9,11]$ showed the presence of a network of interconnected intermetallic through $3 \mathrm{D}$ reconstructed images. The change in the behavior of the offset yield point may, as such, be related 
to the formation of a more or less fully connected network that was achieved at approximately $11 \%$ of $\mathrm{Mg}_{17} \mathrm{Al}_{12}$ fraction. During a tensile test, initial plastic deformation can only occur when the $\mathrm{Mg}_{17} \mathrm{Al}_{12}$ network is deformed. Hence, the formation of an interconnected array of $\mathrm{Mg}_{17} \mathrm{Al}_{12}$ leads to increase of the offset yield strength. It is also suggested that below $9 \%$ of the $\mathrm{Mg}_{17} \mathrm{Al}_{12}$ fraction, this network did not form and as a consequence showed a lower offset yield strength. This effect was valid for both room temperature and at $190{ }^{\circ} \mathrm{C}$.
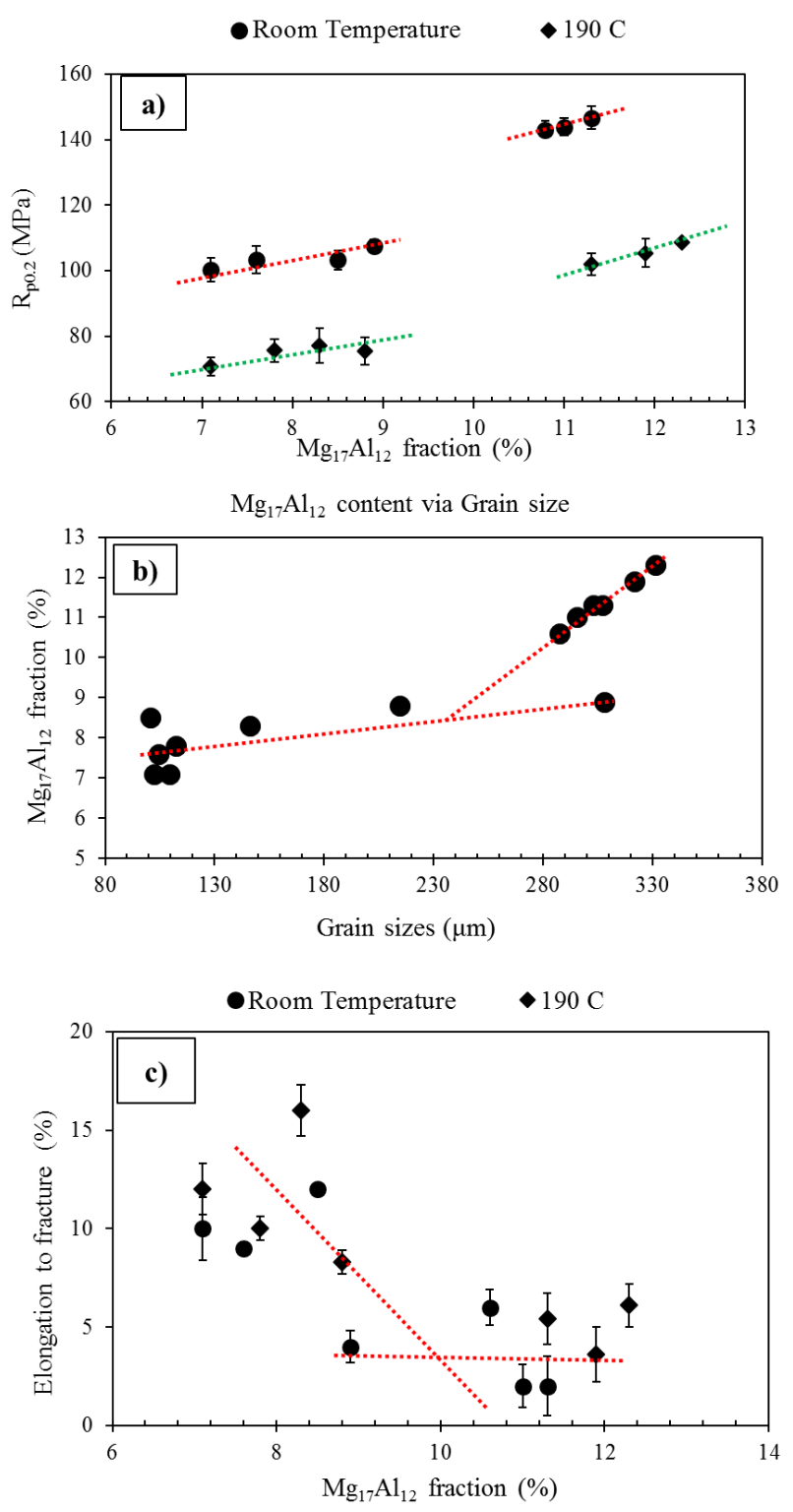

Figure 3. Dependence of (a) $R_{p 0.2}$ and (c) elongation to fracture with fraction of $\mathrm{Mg}_{17} \mathrm{Al}_{12}$ at room temperature and $190{ }^{\circ} \mathrm{C}$ and linear regression plot; (b) Fraction of $\mathrm{Mg}_{17} \mathrm{Al}_{12}$ versus grain size.

In Figure $3 b$, the fraction of $\mathrm{Mg}_{17} \mathrm{Al}_{12}$ is plotted versus grain size. In Figure $3 b$, two different behaviors can be identified. One group shows a weak dependence with the primary grain size, with fractions ranging typically from $7 \%$ to $9 \%$. The other group shows a strong dependence with the grain size, with typical fractions just above $11 \%$. The intersection in slope between these two groups occurs at around $9 \%$ of the intermetallic fraction. The outlier showing a low fraction $\mathrm{Mg}_{17} \mathrm{Al}_{12}$ at a large grain size also has a low $R_{p 0.2}(107 \mathrm{MPa})$, supporting the hypothesis of connectivity and its influence on material yielding. 
Analyzing the elongation to failure, in Figure $3 c$, a clear reduction is seen with an increasing $\mathrm{Mg}_{17} \mathrm{Al}_{12}$ fraction. Above $10 \% \mathrm{Mg}_{17} \mathrm{Al}_{12}$ the elongation to failure appears to be in the order of $4 \%$ with a fair scatter. It can thus be concluded that the yield strength and elongation to failure depended on the fraction of $\mathrm{Mg}_{17} \mathrm{Al}_{12}$.

The ultimate tensile strength did mainly depend on temperature and no statistically significant dependence on grain size, SDAS or $\mathrm{Mg}_{17} \mathrm{Al}_{12}$ fraction could be established. As mentioned above, a finer SDAS appeared to display a higher rate of hardening. In order to analyze this behavior, an apparent toughness index was calculated as $R_{m} \times \varepsilon_{f}$ and plotted against SDAS, in Figure 4. The apparent toughness showed an inverse dependence on SDAS. It should also be noted that the temperature did not shift the influence and all measured values fell on the same line.

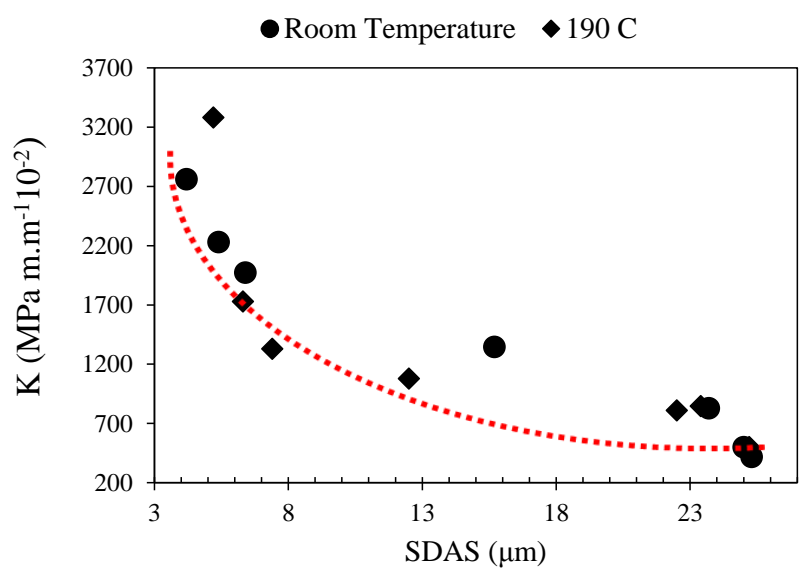

Figure 4. Apparent toughness as a function of SDAS at both room temperature and at $190^{\circ} \mathrm{C}$.

\section{Conclusions}

An attempt to shed light on the influence of the non-equilibrium microstructure on mechanical properties of AZ91D was made through tensile testing of material produced through controlled solidification. The following conclusions can be drawn from the present study:

1 The offset yield strength $\left(R_{p 0.2}\right)$ of AZ91D at a temperature range from Room Temperature (RT) to $190{ }^{\circ} \mathrm{C}$ was strongly related to the fraction of $\mathrm{Mg}_{17} \mathrm{Al}_{12}$ with an abrupt increase occurring between $9 \%$ and $11 \%$.

2 The fraction of $\mathrm{Mg}_{17} \mathrm{Al}_{12}$ showed a strong relation with the primary grain size. Larger primary grains showed higher fractions to be precipitated. At a precipitated fraction above $9 \%$, the dependence on grain size became very strong.

3 The ductility (elongation to failure $\left(\varepsilon_{f}\right)$ ) of AZ91D strongly depended on the fraction of $\mathrm{Mg}_{17} \mathrm{Al}_{12}$. Ductility was reduced with an increased fraction of $\mathrm{Mg}_{17} \mathrm{Al}_{12}$ up to approximately $9 \%$, after which a further ductility decrease was inconclusive.

4 The hardening rate in the tensile tests appeared to be higher for smaller SDAS while no such relation could be seen for the ultimate tensile strength.

5 The apparent toughness showed a strong inverse relation to the SDAS. This relationship was temperature-independent.

Acknowledgments: The authors are acknowledged the Knowledge Foundation for financial support under the CompCAST project (Dnr 2010/0280). Husqvarna AB is also acknowledged for the support with materials.

Author Contributions: H.D., N.-E.A. and A.E.W.J. conceived and designed the experiments; H.D. performed the experiments, analyzed the data and wrote the paper. N.-E.A. and A.E.W.J. contributed with advice on method of analysis.

Conflicts of Interest: The authors declare no conflict of interest. 


\section{References}

1. Friedrich, H.; Schumann, S. Research for a "new age of magnesium" in the automotive industry. J. Mater. Process. Technol. 2001, 117, 276-281. [CrossRef]

2. Lee, C.D. Effect of grain size on the tensile properties of magnesium alloy. Mater. Sci. Eng. A 2007, 459, 355-360. [CrossRef]

3. Cáceres, C.H.; Griffiths, J.R.; Pakdel, A.R.; Davidson, C.J. Microhardness mapping and the hardness-yield strength relationship in high-pressure diecast magnesium alloy AZ91. Mater. Sci. Eng. A 2005, 402, 258-268. [CrossRef]

4. Prakash, D.L.; Regener, D.; Vorster, W. Microscopic failure modes of hpdc AZ91HP magnesium alloy under monotonic loading. Mater. Sci. Eng. A 2008, 488, 303-310. [CrossRef]

5. Caceres, C.H.; Davidson, C.J.; Griffiths, J.R.; Newton, C.L. Effects of solidification rate and ageing on the microstructure and mechanical properties of AZ91 alloy. Mater. Sci. Eng. A 2002, 325, 344-355. [CrossRef]

6. Cerri, E.; Leo, P.; de Marco, P. Hot compression behavior of the AZ91 magnesium alloy produced by high pressure die casting. J. Mater. Process. Technol. 2007, 189, 97-106. [CrossRef]

7. Aghion, E.; Moscovitch, N.; Arnon, A. The correlation between wall thickness and properties of HPDC Magnesium alloys. Mater. Sci. Eng. A 2007, 447, 341-346. [CrossRef]

8. Prakash, D.L.; Regener, D. Quantitative characterization of $\mathrm{Mg}_{17} \mathrm{Al}_{12}$ phase and grain size in HPDC AZ91 magnesium alloy. J. Alloy. Compd. 2008, 461, 139-146. [CrossRef]

9. Nagasekhar, A.; Cáceres, C.; Kong, C. On the development of a pseudo micro-truss intermetallic microstructure in a high pressure die cast AZ91 alloy. In Journal of Physics: Conference Series; IOP Publishing: Bristol, UK, 2010.

10. Amberger, D.; Eisenlohr, P.; Göken, M. Influence of microstructure on creep strength of MRI 230D Mg alloy. In Journal of Physics: Conference Series; IOP Publishing: Bristol, UK, 2010.

11. Nagasekhar, A.; Cáceres, C.; Kong, C. 3D characterization of intermetallics in a high pressure die cast Mg alloy using focused ion beam tomography. Mater. Charact. 2010, 61, 1035-1042. [CrossRef]

12. Cáceres, C.H.; Poole, W.J.; Bowles, A.L.; Davidson, C.J. Section thickness, macrohardness and yield strength in high-pressure diecast magnesium alloy AZ91. Mater. Sci. Eng. A 2005, 402, 269-277. [CrossRef]

13. Cao, H.-P.; Wessén, M. Effect of microstructure on mechanical properties of as-cast Mg-Al alloys. Metall. Mater. Trans. A 2004, 35, 309-319. [CrossRef]

14. Dini, H.; Andersson, N.E.; Jarfors, A. Effects of Microstructure on Deformation Behaviour of AZ91D Cast Alloy. In TMS 2014 Supplemental Proceedings; John Wiley \& Sons, Inc.: Hoboken, NJ, USA, 2014; pp. 565-572.

15. ASTM B557M-10. Standard Methods of Tension Testing Wrought and Cast Aluminum and Magnesium Alloy Products. In Annual Book of ASTM Standards; American Society for testing and Materials: West Conshohocken, PA, USA, 2010.

16. Maltais, A.; Dubé, D.; Fiset, M.; Laroche, G.; Turgeon, S. Improvements in the metallography of as-cast AZ91 alloy. Mater. Charact. 2004, 52, 103-119. [CrossRef]

17. Handbook, A. Metallography and Microstructures; Vander Voort, G.F., Ed.; ASM Intenational: Geauga County, OH, USA, 2004; Volume 9.

18. Standard, A. E112: Standard Test Methods for Determining Average Grain Size; ASM Intenational: West Conshocken, PA, USA, 1996.

19. DeHoff, R.T.; Rhines, F.N. Quantitative Microscopy; McGraw-Hill: New York, NY, USA, 1968.

20. Pickering, F.B. The Basis of Quantitative Metallography; Metals and Metallurgy Trust for the Institute of Metallurgical Technicians: London, UK, 1976.

21. International Organization for Standardization. ISO 9276-6: 2008 (E); ISO: Geneva, Switzerland, 2008.

22. Eliezer, D.; Aghion, E.; Froes, F.S. Magnesium science, technology and applications. Adv. Perform. Mater. 1998, 5, 201-212. [CrossRef]

23. Nave, M.; Dahle, A.; StJohn, D. Eutectic Growth Morphologies in Magnesium-Aluminium Alloys. In Magnesium Technology 2000; John Wiley \& Sons, Inc.: Hoboken, NJ, USA, 2000; pp. 233-242.

24. Nave, M.; Dahle, A.; StJohn, D. The effect of solidification rate on the structure of magnesium-aluminium eutectic grains. Int. J. Cast Met. Res. 2000, 13, 1-7. 
25. Zhang, J.; Guo, Z.X.; Pan, F.; Li, Z.; Luo, X. Effect of composition on the microstructure and mechanical properties of Mg-Zn-Al alloys. Mater. Sci. Eng. A 2007, 456, 43-51. [CrossRef]

26. Dini, H.; Andersson, N.-E.; Ghassemali, E.; Jarfors, A.E.W. Microstructural scale effects on thermal expansion behaviour of cast AZ91D. In Proceedings of the TMS 144th Annual Meeting \& Exhibition, Orlando, FL, USA, 15-19 March 2015; p. 361.

(c) 2016 by the authors; licensee MDPI, Basel, Switzerland. This article is an open access article distributed under the terms and conditions of the Creative Commons Attribution (CC-BY) license (http:/ / creativecommons.org/licenses/by/4.0/). 